\title{
BIOLOGICAL CONTROL OF AFLATOXIGENIC FUNGI ON PEANUT: FOR THE PRE-HARVEST APPROACH
}

\author{
Isılay LAVKOR ${ }^{*}$, Halis ARIOGLU ${ }^{2}$, Isll VAR ${ }^{3}$, Sevcan OZTEMIZ ${ }^{4}$

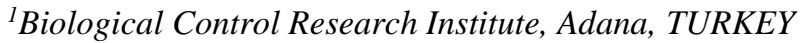 \\ ${ }^{2}$ Cukurova University, Faculty of Agriculture Department of Field Crops, Adana, TURKEY \\ ${ }^{3}$ Cukurova University, Faculty of Agriculture, Department of Food Engineering, Adana, TURKEY \\ ${ }^{4}$ Duzce University, Faculty of Agriculture and Natural Sciences, Department of Plant Protection, Duzce, \\ TURKEY \\ *Corresponding author: lavkor@gmail.com
}

Received: 11.12.2018

\begin{abstract}
This study was carried out to determine the efficacy of different applications of a biopesticide for reduction of aflatoxin contamination in peanut. The biopesticide, afla-guard, delivers a nontoxigenic Aspergillus flavus to the field where it competes with naturally occurring toxigenic fungus. Biocontrol treatments included: (I) soil application during sowing, (II) multiple application during sowing and 40 days after planting, (III) foliar application at 60 days after planting (Iv) control (untreated plots). Biopesiticide was applied to peanut plots in 2015 and 2016 in Randomized Complete Block Design with four replications. Peanuts were collected from control and treated plots at harvest-drying-pre-storage periods and analysed for aflatoxins. Aflatoxin concentrations were generally quite low in 2015 , also the aflatoxin concentration in treated samples (from 0.04 to $0.71 \mu \mathrm{g} / \mathrm{kg}$ ) was reduced by 97.38 to $99.82 \%$ compared with controls (from 21.84 to $27.12 \mu \mathrm{g} / \mathrm{kg}$ ). In 2016 , reductions were also noted for all biocontrol treatments (from 89.07 to $92.39 \%$ ) compared with controls. In conjunction with the reductions in aflatoxin contamination, biocontrol treatments produced significant reductions with biopesticide in peanut. Therefore, it can be said that a biological control method is a promising approach for controlling aflatoxin.
\end{abstract}

Keywords: Aflatoxin, Aspergillus flavus, Aspergillus flavus NRRL 21882, Biological control, Peanuts

\section{INTRODUCTION}

Peanut (Arachis hypogaea L.) is a one-year plant belonging to the Fabaceae family and contains a high level of fat in its seed (Arioglu, 2000). The crop is widely consumed in Turkey, as a rich source of protein and vitamins. However, fungal contamination is a main problem in peanut production. Fungi are the main spoilage agents both various plant pathogens and food. Fungal contamination caused plant infection not only seed contamination with mycotoxins but also results in a decrease of crop yield and significant economic losses of a quality (Makun et al., 2010).

Some fungal species make mycotoxins that are toxic secondary metabolites (Richard, 2007; Russell et al., 2010). Aspergillus flavus and Aspergillus parasiticus are the major aflatoxin producing species on crops (Yu et al., 2004). Aflatoxins are known to be the most carcinogenic among all of the mycotoxins (Singh et al., 2018). Therefore, aflatoxin exposure can be in serious health conditions such as cancer and liver cirrhosis, weakened immune systems (Wu and Khlangwiset, 2010). The more common toxins groups are aflatoxin $B_{1}, B_{2}, G_{1}$ and $G_{2}$; among them aflatoxin $B_{1}$ is themost toxic. International cancer studies are classified by the agency as group 1 carcinogen (IARC, 1993).

Peanuts are the main sources of human exposure to aflatoxin because it is immensely consumed worldwide (13.3 million tons of peanuts were use up in 2001-2003 and expected consumption of 16.32 million tons in 2030) and unfortunately are the most susceptible crop to aflatoxin contamination (Waliyar et al., 2009; Mutegi, 2010; Wu and Khlangwiset, 2010). For this reason, exposure to aflatoxin in peanut represent a serious risk to economy and health for many countries (Kumar et al., 2008; Guo et al., 2009).

A. flavus and A. parasiticus are caused aflatoxin contamination on peanuts. These fungi are contacted developing peanut pods to grow and increase in the soil. When the peanut pods are exposed to drought conditions, they become available to contamination. A method of biological control has used for reducing aflatoxin contamination which nontoxigenic A flavus is applied to 
peanut soil to deport the toxigenic strain. A biopesticide, afla-guard(®), has been developed for controlling aflatoxin in peanuts (Isakeit et al., 2010). This biopesticide supplies of introducing a competitive and nonaflatoxigenic strain of Aspergillus flavus into soils. This commercial product is contained of the nontoxigenic strain of A. flavus conidia, which is applied to peanut fields during the cultivation season. After the conidia germination, growing, and sporulating, increasing population of the nontoxigenic strain in the soil (Dorner, 2004, 2005; Dorner and Lamb, 2006). Therefore, it is seen that biological control is efficient for both pre and postharvest for aflatoxin contamination.

Even though several studies have researched the effects and performance of afla-guard in different countries, any studies on afla-guard haven't been done in Turkey. Particularly, there is no dearth of information about the suitability and adaptability of afla-guard by peanut in Turkey (Lavkor and Bicici, 2015; Lavkor et al., 2017). The purpose of this study was conducted to evaluate the efficacy of three different treatments of nontoxigenic Aspergillus flavus NRRL 21882 to decrease preharvest aflatoxin contamination of peanuts.

\section{MATERIALS AND METHODS}

\section{Materials}

This study has been performed in 2015 and 2016 at the fields of Cukurova University located in Adana, Turkey as a second crop peanut. Halisbey variety belonging to Virginia market type was used as a plant material in this experiment.

\section{Methods}

Aflatoxigenic A. flavus and inoculum preparation: A. flavus isolated from peanut stores in Osmaniye in 2011, which produced $22.67 \mu \mathrm{g} / \mathrm{L} \mathrm{AFB}_{1}, 1.06 \mu \mathrm{g} / \mathrm{L} \mathrm{AFB}_{2}$ and $23.73215 \mu \mathrm{g} / \mathrm{L}$ aflatoxin. Isolates were maintained on Czapekagar slants at $4^{\circ} \mathrm{C}$.

A modified inoculation method according to Denizel and Kosker (1972) was carried out. Aflatoxigenic A. flavus was inoculated on Czapek agar media and incubated at $24^{\circ} \mathrm{C}$ for 4 days. Following which, grains $(300 \mathrm{~g})$ were soaked in $50 \mathrm{ml}$ of distilled water, and they autoclaved for 30 minutes in a $1000 \mathrm{ml}$ flask. After cooling, the grains were incubated for 7 days at $25^{\circ} \mathrm{C}$ with aflatoxigenic strain to allow colonization for further growth and sporulation. The product was colonized with an aflatoxigenic isolate in a flask and blended gently shaking it. Conidial spores were removed from the flask with a long-stemmed sterile spatula. Then spore suspensions of the aflatoxigenic isolate were prepared in $0.1 \%$ Tween 80 , and adjusted the concentration of conidia $10^{7}$ per ml using a hemocytometer. Then, the strain mixture was inoculated with 100 seeds in the flask. At last, aflatoxin producing A. flavus isolate was artificially inoculated with peanut seeds and then sown in the field plots.

Field Plots: Experiment was designed at Randomized Complete Block with four replications with four plots in each block. Each plot consisted of 3 rows $5.0 \mathrm{~m}$ long and $70 \mathrm{~cm}$ apart. Furthermore, the seeds were sown by hand on 18 June April 2015 and 17 June 2016 with 70 x $10 \mathrm{~cm}$ distance. In the experiments, $25 \mathrm{~kg} / \mathrm{da}$ diammonium phosphate (DAP) was used before planting. Also, 30 $\mathrm{kg} / \mathrm{da}$ ammonium nitrate $(33 \% \mathrm{~N})$ was applied two times; before first (flowering period) and second (pod formation) irrigation in each years. After, inoculated seeds with aflatoxigenic $A$. flavus of conidial suspension $\left(1 \times 10^{7}\right.$ conidia/ml) were sown.

Applications of Afla-guard (Aspergillus flavus NRRL 21882): An aqueous conidial suspension of the nontoxigenic A. flavus was applied in three different treatments in the experiment and included; (1) afla-guard applied to soil during sowing at $907 \mathrm{~g} / \mathrm{da}$; (11) afla-guard applied to soil during sowing (455 g/da) and 40 days after planting (455 g/da); (111) afla-guard applied to foliar at 60 days after planting (907 g/da); (1v) Control (untreated plots) (Table 1) (Anonymous, 2014). The experiment also included untreated controls with inoculation of aflatoxigenic A flavus, but not applied afla-guard. The suspension was applied soil and foliar as a spray when good soil moisture is available. This can be soon after a rain or shortly before (if a high probability of rain exists). Even in the absence of rain, good growth of the fungus can take place in the warm, humid environment under the plant canopy if there is good protection from direct sunlight. Afla-Guard ${ }^{\circledR}$ (contains $0.0094 \%$ active ingredient with a minimum of $1.2 \times 10^{8} \mathrm{CFU} / \mathrm{lb}$ ) is a registered trademark of a Syngenta Group Company.

Table 1. Application details of Afla-guard (g/da)

\begin{tabular}{|c|c|c|c|}
\hline \multirow{2}{*}{ Biopesticide } & \multicolumn{2}{|c|}{ Soil Application (g/da) } & \multirow{2}{*}{$\begin{array}{c}\begin{array}{c}\text { Foliar Application } \\
\text { (g/da) }\end{array} \\
\end{array}$} \\
\hline & I. Application & II. Application & \\
\hline \multirow{5}{*}{$\begin{array}{l}\text { Aspergillus flavus NRRL } \\
21882 \% \text { (active ingredient } \\
\% 0.01 \text { ) } \\
1.2 \times 10^{8} \mathrm{cfu} / \mathrm{lb} \\
\text { (Afla-guard) }\end{array}$} & \multirow{5}{*}{$\begin{array}{c}\text { Soil application } \\
\text { during sowing } \\
907 \mathrm{~g} / \mathrm{da}\end{array}$} & Soil application during sowing & \multirow{5}{*}{$\begin{array}{c}\text { Foliar application at } 60 \\
\text { days after planting } \\
907 \mathrm{~g} / \mathrm{da}\end{array}$} \\
\hline & & $455 \mathrm{~g} / \mathrm{da}$ & \\
\hline & & Soil application at 40 days after & \\
\hline & & planting & \\
\hline & & $455 \mathrm{~g} / \mathrm{da}$ & \\
\hline
\end{tabular}

Harvest: The peanut samples were collected at three different periods which included harvest, drying, and prestorage. Peanut plots were harvested on 06 November
2015 and 04 November 2016. After each plot was harvested, the pods were dried in the naturally field conditions for 6-10 days. Then, the peanuts were 
eliminated from soil for the pre-storage period. Later, the peanuts were transferred to storage. About $5 \mathrm{~kg}$ peanuts samples were divided into a paper bag and about $1 \mathrm{~kg}$ of peanut subsamples were collected for aflatoxin analysis. The shells were removed manually. Samples composed of $1 \mathrm{~kg}$ each were manually separated from the shell and were retained at $+4^{\circ} \mathrm{C}$ for aflatoxin analysis (Lavkor, 2013).

Aflatoxins Analyses: The aflatoxins were analyzed by using immunoaffinity columns and aflatoxins $B_{1}, B_{2}, G_{1}$, and $G_{2}$ were affected by High-Performance Liquid Chromatography (HPLC) method in accordance with Arzandeh and Jinap (2011). Peanut samples weighing $50 \mathrm{~g}$ were weighed together with $5 \mathrm{~g}$ of sodium chloride $(\mathrm{NaCl})$ and shaken. Methanol: water $(125 \mathrm{ml})$ in a ratio of 70:30 was added to the jar and the sample was mixed with 2-3 minutes. The mixture sample poured onto a filter paper. Filtered extract of the $15 \mathrm{ml}$ was diluted with water (30 $\mathrm{ml})$. Afterwards, a $1 \mathrm{ml}$ of methanol was eluted at column and the elute was collected in a vial. Solvent flow column rates of $1 \mathrm{ml} / \mathrm{min}$. The Agilent $1100 \mathrm{HPLC}$ system was used. Excitation and emission wavelengths of 360 and 440 $\mathrm{nm}$ was used for fluorescence detector system. HPLC system consisted of C18 column (R-Biopharm Rhône) with a mobile phase of water/acetonitrile/methanol (600:200:300, v/v/v). Flow rate was $1 \mathrm{ml} / \mathrm{min}$; injection volume was $100 \mathrm{ml}$. The HPLC column was maintained at fix temperature $\left(\mathrm{T}=25^{\circ} \mathrm{C}\right)$. All the data were shown as a $\mu \mathrm{g} / \mathrm{kg}$.

Climate Conditions: The average temperature, soil temperature, $10 \mathrm{~cm}$ top soil temperature and relative humidity of the experimental site during the 2015-2016 growing period were given in Table 2 .

As can be seen in the Table 1, the climate data were collected during the growing seasons of 2015 and 2016 in experimental area. The average temperature data during the growing periods in 2015 and 2016 were ranged from $15.20 \mathrm{~mm}$ to $30.10{ }^{\circ} \mathrm{C}$, respectively. $10 \mathrm{~cm}$ soil temperature during the growing periods in 2015 and 2016 were between $15.60{ }^{\circ} \mathrm{C}$ and $35.16^{\circ} \mathrm{C}$, respectively. Soil temperature was ranged from $6.33{ }^{\circ} \mathrm{C}$ to $30.10{ }^{\circ} \mathrm{C}$ in 2015 and $15.20{ }^{\circ} \mathrm{C}$ to $29.88{ }^{\circ} \mathrm{C}$ in 2016 . The relative humidity was ranged from $50.48 \%$ to $69.81 \%$ in 2015 and $51.75 \%$ to $67.50 \%$ in 2016 . The total rainfall was between 0.00 $\mathrm{mm}$ and $65.00 \mathrm{~mm}$ during the growing periods in 2015 and 2016, respectively.

Table 2. Average temperature, soil temperature, $10 \mathrm{~cm}$ top soil temperature and relative humidity of the experimental site during the 2015-2016 growing period (Anonymous, 2017)

\begin{tabular}{|c|c|c|c|c|c|c|c|c|c|c|}
\hline \multirow{3}{*}{ Months } & \multirow{2}{*}{\multicolumn{2}{|c|}{ Average temperature }} & \multirow{2}{*}{\multicolumn{2}{|c|}{$\begin{array}{c}\begin{array}{c}\text { Soil } \\
\text { temperature }\end{array} \\
\left({ }^{0} \mathrm{C}\right)\end{array}$}} & \multicolumn{2}{|c|}{$0 \mathrm{~cm}$ soil temperature } & \multirow{2}{*}{\multicolumn{2}{|c|}{$\begin{array}{c}\begin{array}{c}\text { Relative } \\
\text { humidity }\end{array} \\
(\%)\end{array}$}} & \multirow{2}{*}{\multicolumn{2}{|c|}{$\frac{\text { Total rainfall }}{(\mathrm{mm})}$}} \\
\hline & & & & & & & & & & \\
\hline & 2015 & 2016 & 2015 & 2016 & 2015 & 2016 & 2015 & 2016 & 2015 & 2016 \\
\hline June & 25.15 & 27.29 & 18.24 & 20.17 & 28.28 & 29.95 & 69.11 & 63.79 & 1.60 & 9.12 \\
\hline July & 28.45 & 29.50 & 22.30 & 23.32 & 34.57 & 35.16 & 69.81 & 67.50 & 0.40 & 0.20 \\
\hline August & 30.10 & 29.88 & 23.52 & 23.82 & 35.13 & 35.05 & 62.32 & 67.39 & 5.45 & 8.20 \\
\hline September & 28.72 & 26.15 & 20.82 & 19.16 & 32.05 & 29.19 & 63.55 & 59.92 & 65.00 & 7.96 \\
\hline October & 22.43 & 22.90 & 15.65 & 13.77 & 23.73 & 24.18 & 65.12 & 55.16 & 4.59 & 0.00 \\
\hline November & 16.93 & 15.20 & 6.33 & 4.27 & 16.58 & 15.60 & 50.48 & 51.75 & 3.50 & 3.97 \\
\hline
\end{tabular}

Statistical Analysis: The data were evaluated to analysis of variance (ANOVA). Duncan test $(\mathrm{P}<0.05)$ was compared with the means (Gomez and Gomez, 1983). Statistical analysis was carried out using the statistical package MSTAT-C (1991).

\section{RESULTS AND DISCUSSION}

In the field experiments carried out in two years, three different biocontrol treatments were reduced aflatoxin level signally; also all treatments usually were seemed to result in less aflatoxin in 2015 and 2016 compared with untreated controls. There were statistically expressive differences $(\mathrm{P} \leq 0.05)$ compared groups but no statistically significant $(\mathrm{P} \leq 0.05)$ of all treated plots between each other.

According to the results of the plot experiments, total aflatoxin concentration of peanut samples from harvest, drying, and pre-storage periods showed a difference ranging between 0.04 and $0.71 \mu \mathrm{g} / \mathrm{kg}$, in connection to the results of treated plots in 2015. Aflaguard effects of treated plots were found to be effective between 97.38 and $99.82 \%$ according to Abbot formula
(Table 3, Figure 1). In 2015, there were significant $(\mathrm{P} \leq 0.005)$ effects on aflatoxin contamination by three periods (harvest, drying and pre-harvest) and all biocontrol treatments compared with control plots. When data of aflatoxin concentrations for peanuts in harvest, drying and pre harvest periods are analyzed together, each treatment produced significant reductions compared with the control.

In the second year of the field experiment performed, the effectiveness of plot treatment was different from the control statistically. As in 2015, there was significant $(\mathrm{P} \leq 0.005)$ effect on aflatoxin contamination from the plot treatments under harvest, drying and pre-harvest periods in 2016. In 2016, of the total aflatoxin in treated plots was between 1.79 and 2.87 $\mu \mathrm{g} / \mathrm{kg}$ while the total aflatoxin in control plots was between 23.48 and $26.25 \mu \mathrm{g} / \mathrm{kg}$ in harvest, drying, and pre-storage periods. The aflatoxin concentration decreasing the effect of treated plots was found between 89.07 and $91.64 \%$ (Table 3, Figure 2).

Three different biocontrol treatments were applied under field conditions in Turkey to determine the effectiveness of afla-guard in mitigating aflatoxin contamination of 
peanut. In general it was demonstrated that the biocontrol treatments investigated in this study reduced the aflatoxin in field experiments. This study corroborates previous studies demonstrating the biological control of aflatoxin contamination in peanuts by competitive exclusion (Dorner et al., 1992, 1998; Dorner and Cole, 2002; Pitt and Hocking, 2006; Dorner and Horn; 2007).

Table 3. Effect of biological control treatments on aflatoxin contamination of peanuts in harvest, drying, pre-storage periods in 2015 and 2016

\begin{tabular}{|c|c|c|c|c|c|c|}
\hline \multirow{2}{*}{ Treatment } & Harvest & Drying & Pre-storage & Harvest & Drying & Pre-storage \\
\hline & \multicolumn{3}{|c|}{ Total aflatoxin $(\mu \mathrm{g} / \mathrm{kg})$} & \multicolumn{3}{|c|}{$\%$ Effect (Abbott) } \\
\hline \multicolumn{7}{|c|}{2015} \\
\hline Soil $^{1}$ & $0.04 b^{*}$ & $0.16 b$ & $0.04 \mathrm{~b}$ & 99.82 & 99.41 & 99.82 \\
\hline Multiple $^{2}$ & $0.07 \mathrm{~b}$ & $0.26 b$ & $0.17 b$ & 99.68 & 99.04 & 99.24 \\
\hline Foliar $^{3}$ & $0.34 \mathrm{~b}$ & $0.71 b$ & $0.24 b$ & 98.44 & 97.38 & 98.93 \\
\hline Control & $21.84 \mathrm{a}$ & $27.12 \mathrm{a}$ & $22.49 \mathrm{a}$ & - & - & - \\
\hline \multicolumn{7}{|c|}{2016} \\
\hline Soil & $2.41 \mathrm{~b}$ & $2.60 \mathrm{~b}$ & $1.96 \mathrm{~b}$ & 90.29 & 90.10 & 91.64 \\
\hline Multiple $^{2}$ & $2.14 b$ & $2.45 b$ & $1.79 b$ & 91.38 & 90.66 & 92.39 \\
\hline Foliar $^{3}$ & $2.48 b$ & $2.87 \mathrm{~b}$ & $2.05 b$ & 90.02 & 89.07 & 91.29 \\
\hline Control & $24.81 \mathrm{a}$ & $26.25 \mathrm{a}$ & $23.48 \mathrm{a}$ & - & - & - \\
\hline \multicolumn{7}{|c|}{ 2015-2016 } \\
\hline Soil $^{1}$ & $1.23 \mathrm{~b}$ & $1.38 b$ & $1.00 \mathrm{~b}$ & 95.06 & 94.76 & 95.73 \\
\hline Multiple $^{2}$ & $1.11 \mathrm{~b}$ & $1.36 \mathrm{~b}$ & $0.98 b$ & 95.53 & 94.85 & 95.82 \\
\hline Foliar $^{3}$ & $1.41 \mathrm{~b}$ & $1.79 \mathrm{~b}$ & $1.15 \mathrm{~b}$ & 94.23 & 93.23 & 95.11 \\
\hline Control & $21.33 \mathrm{a}$ & $26,69 \mathrm{a}$ & $22,99 \mathrm{a}$ & & & \\
\hline
\end{tabular}

${ }^{1}$ Afla-guard applied to soil during sowing at $907 \mathrm{~g} / \mathrm{da}$

${ }^{2}$ Afla-guard applied to soil during sowing (455 g/da) and 40 days after planting (455 g/da)

${ }^{3}$ Afla-guard applied to foliar at 60 days after planting $(907 \mathrm{~g} / \mathrm{da})$

*Means within column followed by different letters are significantly different $(\mathrm{P} \leq 0.05)$ according to Duncan multiple range test

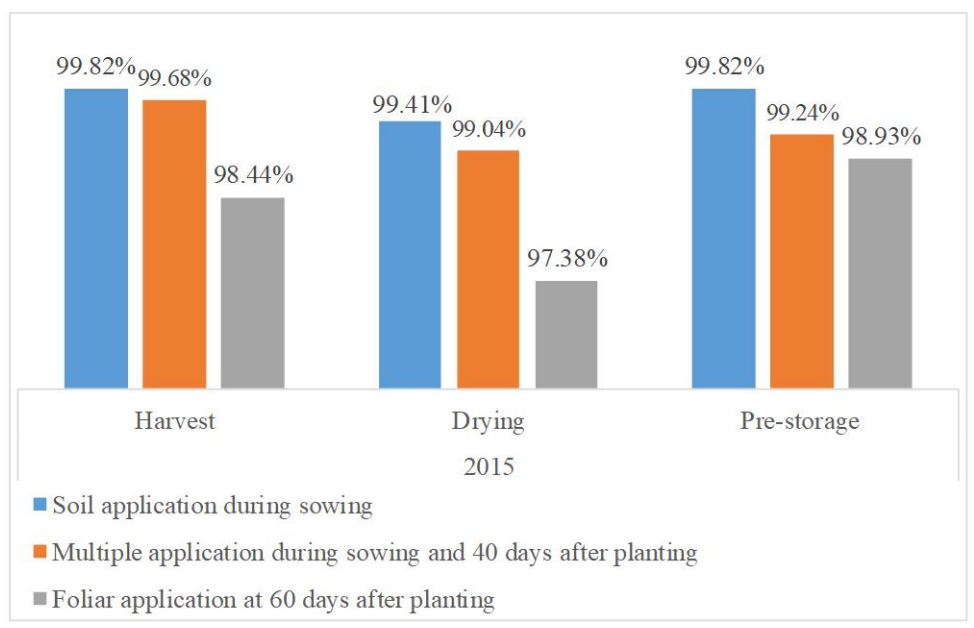

Figure 1. Effect of biological control treatments on aflatoxin contamination of peanuts in harvest, drying, pre-storage periods in 2015

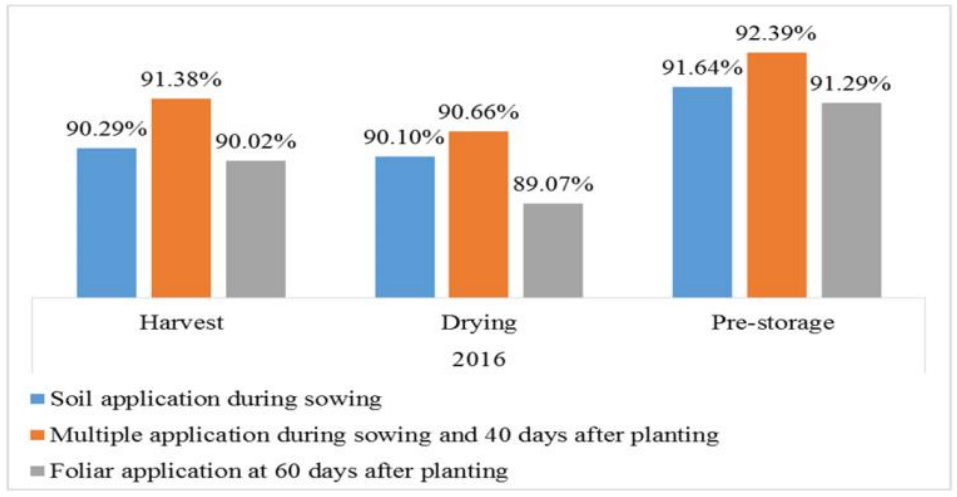


Figure 2. Effect of biological control treatments on aflatoxin contamination of peanuts in harvest, drying, pre-storage periods in 2016 Our results showed that three biocontrol treatments were as effective in reducing aflatoxin contamination. Nevertheless, three biocontrol treatments had similarly affected on the levels of aflatoxin observed. This is the first study to demonstrate that biopesticide has been used to decrease aflatoxin contamination of peanut under field conditions. Also, with this results have been reached solution that address common and serious problem of aflatoxin contamination in peanut field in Turkey.

The reduction of aflatoxin contamination in peanut with applying afla-guard in this study (from 89.07 to $99.82 \%$ ) is similar with different research results. This conclusion is obvious from an examination of the aflatoxin data, particularly for 2015 and 2016, during which significant differences in aflatoxin contamination were not observed in treated plots. With closer examination of all data shows that the various treatments with the nontoxigenic $A$. flavus had a reducing effect on aflatoxin contamination in the treated peanut. There was also no difference in total aflatoxin contamination of peanut among biocontrol treatments. In a previous, similar study testing different biocontrol formulations in peanuts, significant differences were found between controls and treatments for aflatoxin contamination. Also, biocontrol treatments were significantly reduced aflatoxin contamination by $91.6 \%$ in $1997,89.5 \%$ in $1999,98.2 \%$ in the first harvest in 2002 and $98.4 \%$ of the second crop harvest in 2002 in the USA (Dorner, 2004).

For this reason, in our study demonstrated the potential for biocontrol of aflatoxin in peanut, and it did so with application rates that were practically optimum for commercial use. With the current study sought for biocontrol in peanut by using commercially available aflaguard was applied at an economically practical rate (907 $\mathrm{g} / \mathrm{da}$ ). It was also approved the efficacy of three different modes of application.

Moreover, as overall years in 2015 and 2016, aflatoxin data for each biocontrol treatments are given in Table 3. Plot treatments produced significant $(\mathrm{P} \leq 0.05)$ reductions in aflatoxin compared with control plots. Also, treated plots were found to be effective between 93.23 and $95.82 \%$ (Table 3 ). The mean concentration of aflatoxins in peanut from control and treated plots in 2015 and 2016 are shown in Figure 3. Significantly, $(P \leq 0.05)$ aflatoxins decrease was achieved from treated plots. The mean aflatoxin concentration between 0.98 and $1.79 \mathrm{ppb}$ from treated plots in 2015 and 2016 represented a reduction of compared with control plots between 21.33 and 26.69 $\mu \mathrm{g} / \mathrm{kg}$ (Table 3, Figure 3).

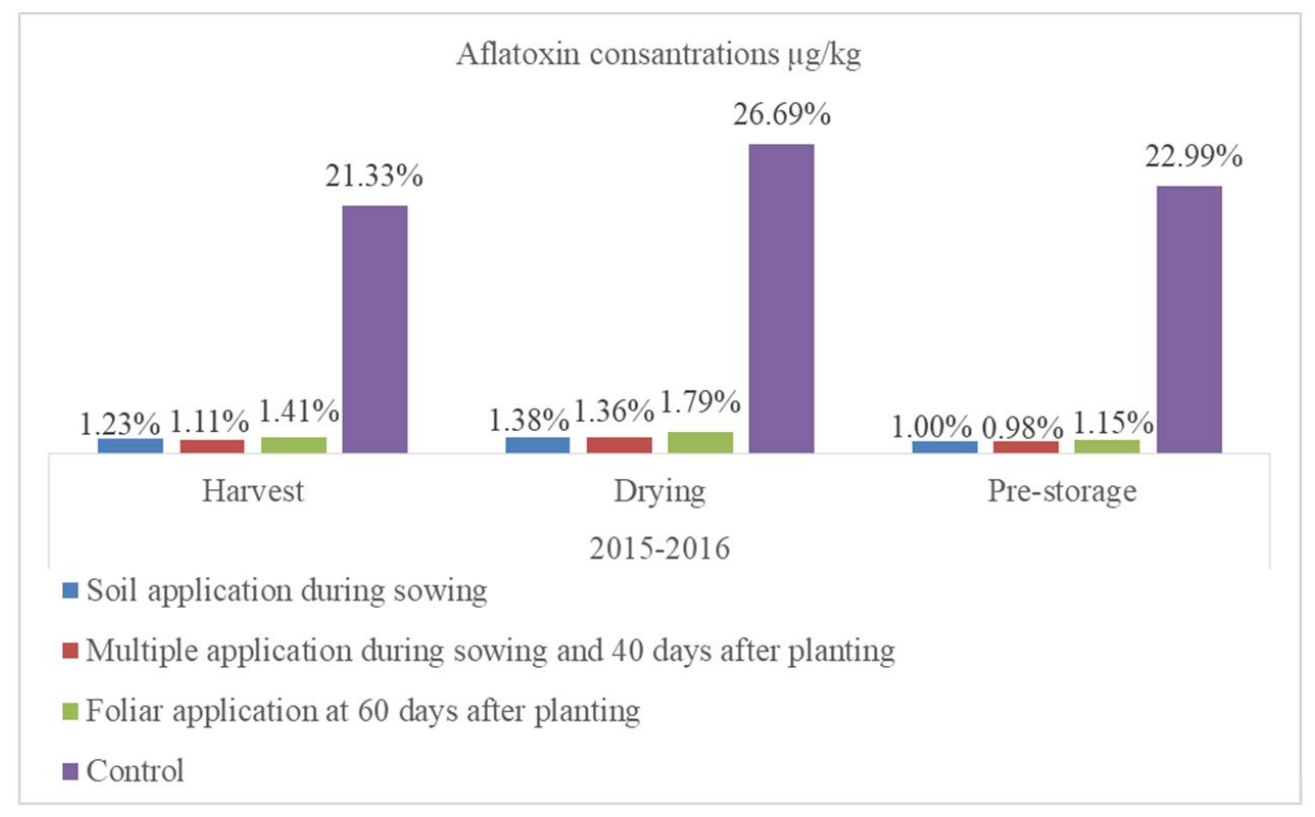

Figure 3. Mean aflatoxin concentrations $(\mu \mathrm{g} / \mathrm{kg})$ of biological control treatments in control and treated plots of peanuts in harvest, drying, pre-storage periods in 2015-2016

Regardless of the conditions experienced in the two years, the overall aflatoxin reductions by $97 \%$ in 2015 and $90 \%$ in 2016 were similarly. These reductions are also similar to the reduction of $85 \%$ produced in peanuts in efficacy study conducted in 2004 (Dorner and Lamb, 2006). Furthermore, other fields and plot studies using the competitive exclusion concept for biological control of aflatoxin contamination have demonstrated aflatoxin reductions ranging from $92 \%$ (Dorner et al., 2003).
Similar results were reported by some other researchers (Dorner, 2004; Dorner and Horn, 2007; Dorner, 2008).

In addition to having demonstrated that competitive exclusion could reduce preharvest aflatoxin contamination, we studied to determine the potential for reductions in contamination that occur during peanut drying and pre-storage periods. Peanuts from control plots were exposed a significant increase in aflatoxin production during drying and pre-storage periods (from 
22.99 to $26.69 \mu \mathrm{g} / \mathrm{kg}$ ) in this study between 2015 and 2016, while aflatoxin levels of peanuts from treated plots contained from 0.98 to $1.79 \mu \mathrm{g} / \mathrm{kg}$ under drying and prestorage periods. Moreover, biocontrol treatments were effectively reduced aflatoxin contamination between 93.23 and $95.82 \%$ under drying and pre-storage periods.

The treatment to the soil of nontoxigenic strains of Aspergillus both decrease levels of preharvest aflatoxin contamination on peanuts (Cole et al., 1989; Dorner et al., 1992; Dorner et al., 1998; Dorner, 2004; Dorner, 2005), and also has a carry-forward impact, decreasing aflatoxin contamination that would be occur during storage (Dorner and Cole, 2002; Dorner, 2009). Dorner (2004) reported that plots of treated and not treated with nontoxigenic strains in 1998 peanut field research were stored in a warehouse and exposed to the storage conditions that could be contaminated with aflatoxin. At the end of this study, peanuts from untreated plots were caused at increasing aflatoxin level during storage (from 0.0 to 78.0 $\mu \mathrm{g} / \mathrm{kg}$ ), while aflatoxin level $1.4 \mu \mathrm{g} / \mathrm{kg}$ in peanuts were detected in treated plots, $98 \%$ reduction of aflatoxin contamination. Thus, reduction of aflatoxin contamination in peanut not only preharvest but also postharvest stages have been a promising approach to the biological control (Dorner et al., 1998; Dorner and Cole, 2002; Dorner, 2010).

Furthermore, the biocontrol applications are based on environmental conditions as a soil temperature (Yin et. al., 2008; Chepsergon et. al, 2014). Soil temperature can major impress both growth and sporulation of the nontoxigenic fungus. A. flavus sporulates at temperatures under $10{ }^{\circ} \mathrm{C}$ on medium in the laboratory, but field experiments displayed that establishment of biocontrol isolates did not consist of easily when soil temperature under $20{ }^{\circ} \mathrm{C}$ (Pitt and Hocking, 2006). The results point out that application of nontoxigenic isolates to soil should be held up until soil temperature reaches at least $20^{\circ} \mathrm{C}$. In Arizona, USA, later April and early June are the appropriate time for application of the nontoxigenic biocontrol strain. A lot of studies performed in Georgia, the biocontrol strain NRRL21882 was applied between 50 and 70 day after planting of peanuts (Dorner et al., 1992; 1998; Dorner, 2004). A similar relationship holds for our region.

As a result, this study is conducted for the first time in Turkey show that biological control methods may have no adverse efficacy on the human and environment health and are efficient options for aflatoxin contamination. Furthermore, afla-guard, which suppresses the contamination of aflatoxin, has been identified for the first time in our country by this study to be applied in peanut crop cultivation. For this purpose, it has been determined that biopesticide, which has been applied in three treatment in the cultivation of peanuts, decreased aflatoxin contamination in the rates ranging from $89.1 \%$ to $99.8 \%$. Therefore, our research study has shown that this biological control strategy can produce reductions in aflatoxin contamination. This study also showed that the displacement of toxigenic strains by nontoxigenic strains that occurs in the field prevents significant aflatoxin contamination when conditions during harvest, drying and pre-storage periods facilitate A. flavus growth. As a result, it has been determined that afla-guard is an effective ingredient biopesticide, and can be used to prevent aflatoxin contamination on peanuts. With this research result, scientific data on biological control and prevention of aflatoxin contamination has been obtained for integrated pest management programs to be applied in peanut cultivation.

\section{ACKNOWLEDGMENTS}

This study (Project No 1150007) was financial supported by The Scientific Technological Research Council of Turkey (TUBITAK).

\section{LITERATURE CITED}

Anonymous, 2014. http://www.syngenta-us.com/currentlabel/afla-guard-gr. Afla-Guard ${ }^{\circledR}$ GR

Anonymous, 2017. The meteorological data for Adana. The Turkish State Meteorological Service Adana Regional Directorship, 2015, 2016.

Arioglu, H. 2000. Peanuts cultivation breeding. Adana, Turkey: Cukurova University Faculty of Agriculture publishing.

Arzandeh, S. and S. Jinap. 2011. Effect of initial aflatoxin concentration, heating time and roasting temperature on aflatoxin reduction in contaminated peanuts and process optimization using response surface modeling. Int. J. Food Sci. Technol. 46: 485-491.

Atehnkeng, J., P.S. Ojiambob, P.J. Cotty and R. Bandyopadhyay. 2014. Field efficacy of a mixture of atoxigenic Aspergillus flavus Link: FR vegetative compatibility groups in preventing aflatoxin contamination in maize (Zea mays L.). Biol. Control, 72: 62-70.

Chepsergon, J., E.K. Kiprop, L.A. Mwamburi. Biocontrol of aflatoxins in corn using atoxigenic Aspergillus flavus. Review International Journal of Science and Research. 12:1954-1958.

Cole, R.J., T.H. Sanders, J.W. Dorner and P.D. Blankenship. 1989. Environmental conditions required to induce preharvest aflatoxin contamination of groundnuts: Summary of six years' research. In: Aflatoxin contamination of groundnut: Proceedings of the international workshop, ed. Hall SD., 279-287, ICRISAT Center, Patancheru, AP, India.

Denizel, T. and O. Kosker. 1972. A mycological survey of various kinds of nuts commercially available in the UK with reference to mycotoxins. University of Ankara, Turkey: Yearbook of the Faculty of Agriculture.

Dorner, J.W., R.J. Cole and P.D. Blankenship. 1992. Use of a biocompetitive agent to control preharvest aflatoxin in drought stressed peanuts. J. Food Prot. 55: 888-892.

Dorner, J.W., R.J. Cole and P.D. Blankenship. 1998. Effect of inoculum rate of biological control agents on preharvest aflatoxin contamination of peanuts. Biol. Cont. 12: 171-176.

Dorner, J.W. and R.J. Cole. 2002. Effect of application of nontoxigenic strains of Aspergillus flavus and A. parasiticus on subsequent aflatoxin contamination of peanuts in storage. J. Stored Prod. Res. 38: 329-339.

Dorner, J.W., R.J. Cole, W.J. Connick, D.J. Daigle, M.R. Mcguire and B.S. Shashac. 2003. Evaluation of biological control formulations to reduce aflatoxin contamination in peanuts. Biol. Cont. 26: 318-324.

Dorner, J.W. 2004. Combined effects of biological control formulations, cultivars, and fungicides on preharvest 
colonization and aflatoxin contamination of peanuts by Aspergillus species. Peanut Sci. 31: 79-86.

Dorner, J.W. 2005. Biological control of aflatoxin crop contamination. In: Aflatoxin and food safety, ed. Abbas H.K., 333-352, Taylor and Francis, New York, USA.

Dorner, J.W. and M.C. Lamb. 2006. Development and commercial use of Afla-Guard(®) an aflatoxin biocontrol agent. Mycotoxin Res. 22: 33-38.

Dorner, J.W. and B.W. Horn. 2007. Separate and combined applications of nontoxigenic Aspergillus flavus and $A$. parasiticus for biocontrol of aflatoxin in peanuts. Mycopathologia 163:215-223.

Dorner, J.W. 2008. Management and prevention of mycotoxins in peanuts. Food Additives and Contaminants. 25: 203-208.

Dorner, J.W. 2009. Development of biocontrol technology to manage aflatoxin contamination in peanuts. Peanut Sci. 36: 60-67.

Dorner, J.W. 2010. Efficacy of a biopesticide for control of aflatoxins in corn. J. Food Prot. 73: 495-499.

Gomez, A.K. and A.A. Gomez. 1983. Statistical Procedures for Agricultural Research. New York: USA: Wiley.

IARC. 1993. Some naturally occurring substances: food items and constituents, heterocyclic aromatic amines and mycotoxins. International Agency for Research on Cancer. http://monographs.iarc.fr/ENG/Monographs/vol56/mono56.p df, (Accessed 21 June 2017)

Isakeit, T., S. Murray and K. Mayfield. 2010. Efficacy of AflaGuard (Aspergillus flavus NRRL 21882) to control aflatoxin on corn in Burleson County, Texas, 2009. Plant Disease Management Reports 4: FC081. www. plantmanagementnetwork.org/pub/trial/PDMR/reports /2010/FC081.pdf, (Accessed January 20, 2018)

Kumar, V., M.S. Basu and T.P. Rajendran. 2008. Mycotoxin research and mycoflora in some commercially important agricultural commodities. Crop Prot. 27: 891-905.

Lavkor, I. 2013. Control of diseases and aflatoxin occurrences with proper cultural and disease management practices in peanut growing. Ph.D. Cukurova University, Adana, p. 300.

Lavkor, I. and M. Bicici. 2015. Aflatoxin occurrence in peanuts grown in Osmaniye at harvest, post-harvest, drying and prestorage periods. J. Agric. Sci. 21: 394-405.
Lavkor, I., I. Var, S. Oztemiz and M. Almatar. 2017. First report of mycotoxins in second peanuts crop in Adana and Osmaniye at harvest, drying, pre-storage and storage periods. In: Aflatoxin-Control, Analysis, Detection and Health Risks, ed. Abdulra'uf L B, 193-208. InTech Open Science, Rijeka, Croatia.

Makun, H.A., S.T. Anjorin, B. Moronfoye, F. Adejo, O.A. Afolabi, G. Fagbayibo, B.O. Balogun, and A.A. Surajudeen. 2010. Fungal and aflatoxin contamination of some human food commodities in Nigeria. Afr. J. Food Sci. 4: 127-135.

Mutegi, C.K., H.K. Ngugi, S.L. Hendiks and R.B. Jones. 2012. Factors associated with the incidence of Aspergillus section Flavi and aflatoxins contamination of peanuts in Busia and Homa bay districts of Western Kenya. Plant Pathol. J. 61: 1143-1153.

Pitt, J.I. and Hocking, A.D. 2006. Mycotoxins in Australia: biocontrol of aflatoxin in peanuts. Mycopathologia, 162: 233-243

Richard, J.L. 2007. Some major mycotoxins and their mycotoxicoses- an overview. Int. J. Food Microbiol. 119: 310.

Russell, R., M. Paterson and N. Lima. 2010. How the climate change affect mycotoxins in food? Food Res. Int. 43: 19021914.

Sigh, P., J. March and P.J. Cotty. Aspergillus texensis: a novel aflatoxin producer with $\mathrm{S}$ morphology from the United States. Toxins 2018, 10, 513.

Waliyar, F., S.V. Reddy and P.L. Kumar. 2009. Review of immunological methods for the quantification of aflatoxins in peanut and other foods. Peanut Sci. 36: 54-59.

Wu, F. and P. Khlangwiset. 2010. Health economic impacts and cost-effectiveness of aflatoxin reduction strategies in Africa: Case studies in biocontrol and postharvest interventions. Food Addit. Contam. A. 27: 496-509.

Yu, J., P.K. Chang, K.C. Ehrlich, J.W. Cary, D. Bhatnagar, T.E. Cleveland, G.A. Payne, J.E. Linz, J.E., C.P. Woloshuk and J.W. Bennett. 2004. Clustered pathway genes in aflatoxin biosynthesis. Appl. Environ. Microbiol. 70: 1253-1262.

Yin, Y., L. Yan, J. Jiang and Z. Ma.2008. Biological control of aflatoxin contamination of crops. Journal of Zhejiang University, Science B.9:787-792. 